\title{
Controlling occupational cancers in Australia
}

\section{We have no strategy for measuring rates, mitigating risk and meeting individuals' needs}

W ork-related cancer attracts considerable public and media attention, but has received limited attention from researchers and policymakers in Australia, particularly in comparison to other cancers, such as those related to tobacco use and sun exposure. During the 1980s, the National Health and Medical Research Council (NHMRC) issued model regulations for the control of carcinogenic substances, and the National Occupational Health and Safety Commission (NOHSC) was formed to coordinate efforts to improve OHS. Policies and strategies on occupational cancer were developed by the NOHSC, and the Australian Mesothelioma Registry was funded. In 2005, the NOHSC was replaced by the Australian Safety and Compensation Council (ASCC). ${ }^{1}$ In turn, in 2008 the ASCC was replaced by Safe Work Australia, which has the primary responsibility of "improving work health and safety and workers' compensation arrangements across Australia". ${ }^{2}$ Despite these initiatives, little progress has been made on Australia's regulatory approach to occupational carcinogen exposure.

The number of cancers resulting from occupational exposures is difficult to estimate. Occupational cancers are not easily identifiable, as they have no unique pathological or clinical features and the lag time between exposure and cancer diagnosis may be decades. There is no unique independent system for collection of data on work-related cancers, and compensation data are of little help because of considerable underclaiming. By applying European attributable fraction estimates to Australian employment data, it has been estimated that about 5000 cancers a year are caused by occupational exposures. ${ }^{3}$ In making this estimate, major assumptions needed to be made regarding the frequency and extent of exposure to occupational carcinogens in Australian industry, since definitive local information is lacking.

\section{International best practice}

In Australia, there is limited systematic work aimed at identifying occupational carcinogens, informing users about carcinogenic risks, and reducing the use of chemicals in industry. Internationally, there are several such initiatives that could be considered for the Australian context.

A number of authoritative independent agencies, such as the International Agency for Research on Cancer, have programs that review evidence regarding potential carcinogens and classify agents according to their carcinogenic potential. ${ }^{4}$ Other agencies, such as the
American Conference of Governmental Industrial Hygienists $^{5}$ and the United States National Toxicology Program, ${ }^{6}$ classify agents with respect to carcinogenicity and set occupational and general population exposure standards that are regularly updated and revised. Germany maintains a database of international exposure limits for chemical agents. ${ }^{7}$ Australian regulations related to carcinogens make use of these international classifications when identifying carcinogenic substances (eg, the Australian Model Work Health and Safety Regulations contain a limited schedule of nine prohibited and 11 restricted carcinogens) ${ }^{8}$ However, there is no system to regularly update regulations and schedules based on best international knowledge.

The United Nations Globally Harmonized System of Classification and Labelling of Chemicals (GHS) is being adopted internationally. ${ }^{9}$ The GHS classifies chemicals by type of hazard (including carcinogenicity) and proposes standard labels and safety data sheets containing information on physical hazards and toxicity. The proposed Australian Model Work Health and Safety Regulations implement the GHS for chemical classification and hazard communication requirements.

The European Union (EU) introduced legislation in 2007 for the registration, evaluation, authorisation and restriction of chemicals (REACH) ${ }^{10}$ The REACH approach is based on the premise of "no data, no use". That is, toxicological and epidemiological data must be provided for substances manufactured or imported into the EU in excess of 1 tonne. For some substances, derived no-effect levels (DNELs) for workers and the general population must be set. No human health effects are expected if exposure is kept below the relevant DNEL. REACH does not apply outside the EU, but it does apply to all substances on the EU market, including those imported from Australia.

A very successful example of legislation aimed at reducing exposure to toxic agents (including some carcinogens) is the Massachusetts Toxics Use Reduction Act (TURA). ${ }^{11}$ Under TURA, a list of toxic or hazardous substances ("toxics") has been created, and any firm that uses, generates or imports any of these must prepare a toxics use reduction plan, report the quantities of toxics they deal with and pay a levy based on the quantity reported. An institute was established to provide resources and tools to support the TURA, including education, community outreach, research into less toxic alternatives, and incentives. ${ }^{12}$ Between 1990 and 2009, and after adjusting for production decreases, reports to the program showed that emissions decreased by $56 \%$ and use of toxic chemicals decreased by $21 \% .^{13}$

Another legislative approach to reducing carcinogen exposure was introduced in Finland in 1979. Companies and institutions are required to report workplace exposures to specific carcinogens to a public register. The aim is to reduce the risk of occupational cancers by improving the 
identification, assessment and elimination of workplace carcinogens. Between 2000 and 2004, the register received, on average, 25109 notifications of exposed workers, representing 39300 exposure events annually. ${ }^{14}$

\section{A plan of action for Australia}

Strategic action aimed at reducing the burden of occupational cancer in Australia needs to be concentrated around three aspects: raising the profile of occupational cancer; interventions to reduce exposure to carcinogens, supported by legislative processes; and improving the support for patients with occupation-related cancer.

\section{Raising the profile of the prevention of occupational cancer as a priority issue}

To prioritise preventive activity, it will be essential to collect data on the number of workers in Australia who are exposed to carcinogens, what industries they are in, and the concentration and frequency of exposures. Several possible sources of data exist. The National Industrial Chemicals Notification and Assessment Scheme is the Australian Government authority responsible for assessing (but not regulating) health and environmental impacts of industrial chemicals. ${ }^{15}$ The National Pollutant Inventory publishes data on annual emissions of 93 specific chemicals generated in Australia. ${ }^{16}$ In addition, Safe Work Australia publishes some research relating to workplace health and safety and workers' compensation. ${ }^{8}$ None of these sources contain good estimates of the number of workers exposed to a particular carcinogen. The establishment and resourcing of an effective national database with the appropriate powers to gather and report the appropriate data may be necessary. However, the current multiagency and multijurisdictional approach to the regulation of carcinogens makes such a national approach difficult. Of note, in 2009, the federal government established the Standing Committee on Chemicals - an interdepartmental group that aims to achieve an effective and efficient national system of chemicals and plastics regulation. ${ }^{17}$

\section{Further development of legislative, regulatory and policy processes}

It is important that Australia applies the highest standards of worker protection, based on the best international evidence. While workplace health and safety is a state responsibility, it is not appropriate that some states have worse protection for workers than others, or that the implementation and enforcement of the national regulations should vary between states and territories. The Model Work Health and Safety Regulations and model Codes of Practice were developed to harmonise regulations across the country; however, concern exists first, to ensure that the highest health and safety standards apply in these revised regulations and, second, to ensure they are adopted by all jurisdictions. ${ }^{8}$

Australia should not lag behind global best practice in reducing exposure to carcinogens. Australian authorities should establish effective processes to review international decisions on carcinogens in a timely manner and introduce appropriate changes to the local workplace. We should also investigate the feasibility of introducing initiatives that are known to be successful in reducing carcinogen exposure, such as TURA or the Finnish exposure register.

A potential effect of introducing stricter legislation in Australia may be to move manufacturing and processing offshore to countries with less stringent regulations. ${ }^{18}$ Mechanisms to address these concerns can be found in trade and international agreements, and Australia needs be active in these forums. ${ }^{19}$

\section{Monitoring and meeting the needs of individuals exposed to occupational carcinogens}

The issue of workplace exposure to carcinogens has the potential for being both under- and overemphasised. Reliable information needs to be easily accessible for workers, employers, consumers, and the media. Media coverage about suspected "cancer clusters" without evidence or investigation can promulgate anxiety when there is low (if any) real risk. ${ }^{20}$ Cancer Council Australia has developed a position statement on occupational carcinogens. ${ }^{21}$

The Asturias Declaration, developed by the World Health Organization, recommends that all countries develop education campaigns to improve public knowledge of environmental causes of cancer and strategies for prevention. ${ }^{22}$ General practitioners and other relevant clinicians need to know how to take a thorough occupational exposure history, and to improve their confidence in identifying whether cancers may be occupationally caused. An Australian list of priority carcinogens, with easy availability of reliable information, relevant to clinicians (such as is being produced by CAREX Canada) would be helpful. ${ }^{23}$ Workers and medical staff are not always aware of the potential for compensation and the processes for gaining it. Effective identification of and compensation for cases of work-related cancer would provide necessary support to affected cancer patients and an increased incentive for insurers, government and industry to minimise the occurrence of such cases.

Poor awareness of exposure to occupational carcinogens and lack of attribution of cancer to occupational causes, among both the clinical and general community, limits opportunities to reduce the likelihood and extent of exposure. In addition, potentially legitimate compensation cases are not pursued. ${ }^{24}$

In Australia, the currently limited and fragmented approach to the process of minimising workplace cancer risk is a significant obstacle to collecting and reporting data on exposure to carcinogens, and an even greater challenge to reducing such exposures.

A strategic approach to this task requires the development of partnerships between unions, government and industry, consumers, non-government organisations, cancer clinicians, occupational physicians and the environmental movement. In addition, audits and reviews should be instigated to determine what is being done to introduce best practice to Australia.

Competing interests: No relevant disclosures.

Provenance: Not commissioned; externally peer reviewed. 
1 The Parliament of the Commonwealth of Australia, House of Representatives. Australian Workplace Safety Standards Bill 2005.

2 Safe Work Australia. About Safe Work Australia. Canberra: Commonwealth of Australia, 2010. http://www.safeworkaustralia.gov.au/ABOUTSAFEWORK AUSTRALIA/Pages/AboutSafeWorkAustralia.aspx (accessed Jun 2011).

3 Fritschi L, Driscoll T. Cancer due to occupation in Australia. Aust NZ J Public Health 2006; 30: 213-219.

4 International Agency for Research on Cancer. IARC monographs on the evaluation of carcinogenic risks to humans. Preamble. Lyon: World Health Organization; 2006. http://monographs.iarc.fr/ENG/Preamble/index.php (accessed Sep 2010).

5 American Conference of Governmental Industrial Hygienists. About ACGIH. Cincinnatti: ACGIH [last updated 2008]. http://www.acgih.org/About/ (accessed Jun 2011).

6 US Department of Health and Human Services, Public Health Service, National Toxicology Program. About the NTP. 2005. http://ntp.niehs.nih.gov/ ?objectid=7201637B-BDB7-CEBA-F57E39896A08F1BB (accessed Jan 2012).

7 Institut fur Arbeitsschutz der Deutschen Gesetzlichen Unfallversicherung (IFA). GESTIS - International limit values for chemical agents. Sankt Augustin: IFA, 2011. http://www.dguv.de/ifa/en/gestis/limit_values/index.jsp (accessed Jul 2011).

8 Safe Work Australia. Model work health and safety regulations; model codes of practice. Canberra: SWA, 2010. http://www.safeworkaustralia.gov.au/ Pages/default.aspx (accessed Jul 2011).

9 United Nations Economic Commission for Europe. Globally harmonized system of classification and labelling of chemicals (GHS). Geneva: UNECE, 2008. http://live.unece.org/trans/danger/publi/ghs/ghs_welcome_e.html (accessed Jun 2011).

10 Environment Directorate General. REACH in brief. Brussels: European Commission, 2007. http://ec.europa.eu/environment/chemicals/reach/pdf/ 2007_02_reach_in_brief.pdf (accessed Jan 2012).

11 Toxics Use Reduction Institute. TURA (Toxics Use Reduction Act) overview. Lowell, Mass: University of Massachusetts Lowell, 2010. http://www.turi.org/ About/Toxics_Use_Reduction_Act2/TURA_Overview (accessed Jun 2011).

12 Dunagan SC, Dodson RE, Rudel RA, Brody JG. Toxics use reduction in the home: lessons learned from household exposure studies. J Cleaner Production [internet] 2011; 19: 438-444.
13 Toxics Use Reduction Institute. Results to date. Lowell, Mass: University of Massachusetts Lowell, 2008. http://turadata.turi.org/Success/index.html (accessed 2Jun 2011).

14 Kauppinen T, Saalo A, Pukkala E, et al. Evaluation of a national register on occupational exposure to carcinogens: effectiveness in the prevention of occupational cancer, and cancer risks among the exposed workers. Ann Occup Hyg 2007; 51: 463-470.

15 National Industrial Chemicals Notification and Assessment Scheme (NICNAS). Australian high volume industrial chemicals list (AHVICL). Sydney: Australian Government Department of Health and Ageing, 2002. http:// nicnas.gov.au/Industry/Australian_High_Volume_Industrial_Chemicals.asp (accessed Sep 2010).

16 National Pollutant Inventory. Substance fact sheets. Canberra: Australian Government Department of Sustainability, Environment, Water, Population and Communities, 2010. http://www.npi.gov.au/substances/factsheets.html (accessed Sep 2010)

17 Department of Innovation, Industry, Science and Research. Standing Committee on Chemicals. Canberra: DIISR, 2011. http://www.innovation. gov.au/INDUSTRY/CHEMICALSANDPLASTICS/SCOC/Pages/default.aspx (accessed Sep 2011).

18 World Health Organization. Primary prevention of cancer through mitigation of environmental and occupational determinants. International Conference on Environmental and Occupational Determinants of Cancer: Interventions for Primary Prevention; 2011 Mar 17-18; Asturias, Spain: WHO, 2011.

19 Australian Government Department of Agriculture, Fisheries and Forestry. Chemicals subject to the Stockholm and Rotterdam Conventions. Canberra: DAFF, 2010. http://www.daff.gov.au/agriculture-food/ag-vet-chemicals/ stockholm-rotterdam (accessed Oct 2010).

20 Purvis Cooper C, Wingo PA, Clutter GG, et al. News coverage of cancer clusters: the cancer registry perspective. Epidemiology [internet] 2004; 15: S197-S198.

21 Cancer Council Australia. Position statement on occupational carcinogens. Sydney: Cancer Council Australia, 2008 http://www.cancer.org.au/policy/ positionstatements/OccupationalCarcinogens.htm (accessed Sep 2011).

22 Landrigan PJ, Espina C, Neira M. Global prevention of environmental and occupational cancer. Environ Health Perspect 2011; 119: a280-a281.

23 CAREX Canada. Surveillance of environmental and occupational exposures for cancer prevention. 2011. http://www.carexcanada.ca/en/ (accessed Sep 2011)

24 Cherrie JW. Reducing occupational exposure to chemical carcinogens. Occup Med 2009; 59: 96-100. 